\title{
The Influence of Community Opening on Road Capacity
}

\author{
An'En He \\ School of Environmental Science and Engineering, North China Electric Power University, Baoding \\ 071000, China. \\ 751397618@qq.com
}

Keywords: road traffic capacity, Community open, road optimization

\begin{abstract}
The smooth flow of the road is in close contact with the convenience of people traveling. The impact of closed communities on urban road capacity has become a hot spot in recent days. This paper aims to improve the existing model to explore the impact of community openness on road capacity.
\end{abstract}

\section{Introduction}

Road capacity refers to the ability of road infrastructure can ease the traffic flow. However, the previous calculation formulas are only for closed cell sections, and the influence of open cells on traffic capacity is not considered. This paper aims to consider the impact of community openness on road traffic capacity and attempts to revise the road capacity model. We try to establish a new mathematical model based on the open-area road capacity to study the impact of the open area on road capacity.

\section{Construct a grid community}

According to China's urban road planning, most of the roads are grid network structure, and more communities can be approximated as rectangles. Therefore, it is very representative and realistic to study the influence of square community on urban transportation network. Combined with this feature, this paper first constructs a grid community using AutoCAD, as shown in Figure 1.

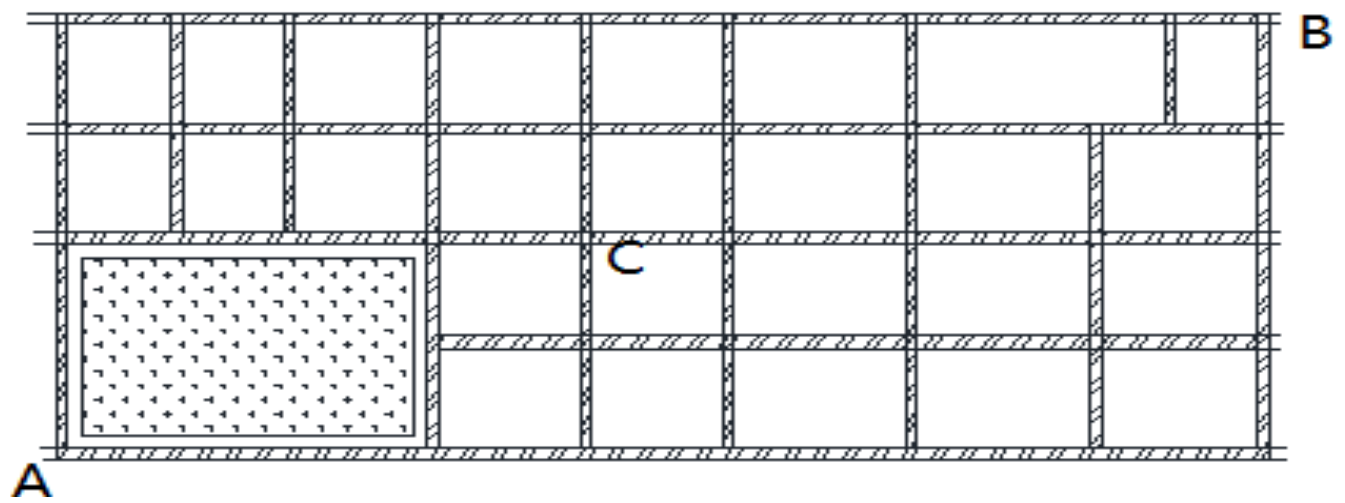

Figure 1 The ideal grid network community

In the figure, the bar section is a road, and the lower left area is a cell (unopened).

\section{Definition of road optimization degree}

First, the new definition of a measure of community openness to the degree of contribution to the road - the degree of road optimization.

For the sake of discussion, it is assumed that the section has only one square community, and the area of the cell and the location in the grid are uncertain. Let $\mathrm{S}(\mathrm{X}, \mathrm{Y})$ denote the square community, $\mathrm{X}$ is its vertical node number, and $\mathrm{Y}$ is its horizontal node number. $\mathrm{N}_{0}$ is the optimal number of paths from $A$ to $B$ when $S$ is open, and $N_{1}$ is the optimal number of paths from $A$ to $B$ (A and $B$ are not in $S$ ) when $S$ is closed. The definition of road optimization is as follows: 


$$
\eta=\frac{N_{0}-N_{1}}{N_{0}}
$$

The meaning of the above formula is due to the opening of the square community, resulting in any number of optimal paths between any two points on the grid network as the proportion of the optimal number of paths after opening. This indicator mainly reflects the contribution rate of the square community to the road system after its opening. The greater the contribution rate, the community open to the surrounding road traffic has a more positive impact. The above formula partially reflects the contribution of square communities to road network traffic. But the impact of the same location of the square community on the optimal number of paths between different starting points and different destinations is different. It is necessary to consider the effect of the square community on the optimal number of paths between all points on the road network in order to reflect the contribution of the community to the whole road network traffic. So, change the above formula to:

The improved formula from the overall reflection of the square community is open to the contribution rate of road network traffic. Through the calculation and analysis of the two formulas, we can get the impact of community openness on the surrounding roads.

$$
\eta^{\prime}=\frac{\sum N_{0}-\sum N_{1}}{\sum N_{0}}
$$

\section{Use road optimization to analyze}

Taking the grid community constructed in Figure 1 and its nearby road map as an example, the community size is $700 \mathrm{~m} * 300 \mathrm{~m}$, and there are five horizontal roads and eight vertical roads around the community. If the pedestrian intends to go from A to C, only two options are north or east, no other choice. If there is traffic jam at this time, there is no alternative path, the road traffic capacity dropped sharply.

According to the above analysis, it is easy to calculate that the optimal number of paths between $A$ and $C$ is 4, and the number of optimal paths between A and B is 171.

a. If the community is semi-open, that is, only a vertical road (Figure 2).

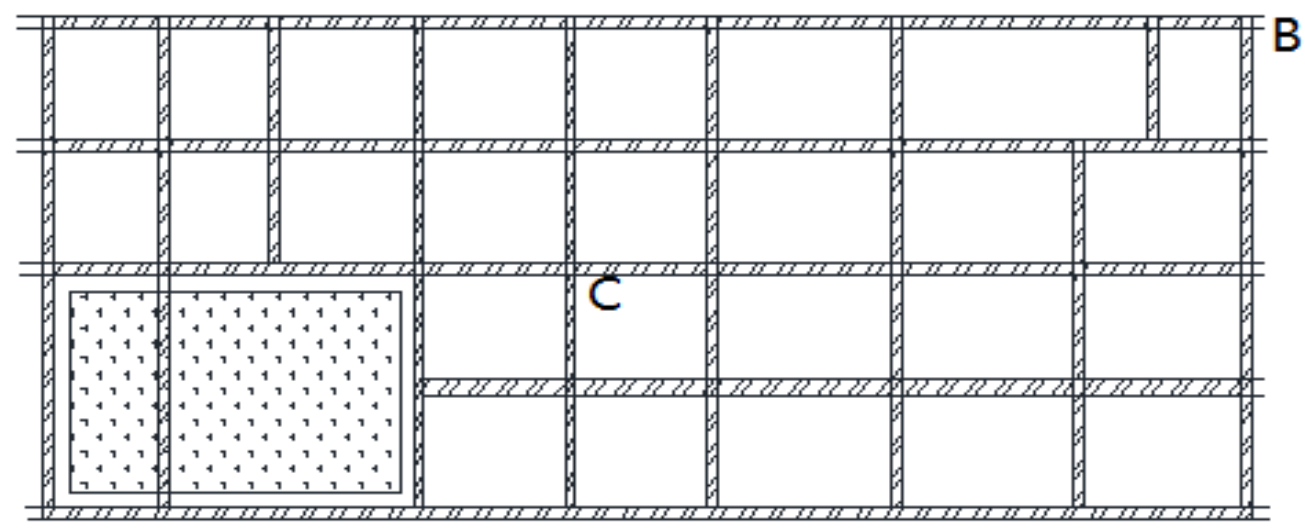

A

Figure2 Only open a vertical road

We can see from Figure 2, an increase in a vertical road, the vehicle gets shunt, reduce traffic pressure and ease traffic congestion.Through the calculation, the optimal number of paths between $\mathrm{A}$ and $\mathrm{C}$ becomes 5, and the number of optimal paths between A and B becomes 207. 
b. If the community is semi-open, that is, only open a horizontal road (Figure 3).

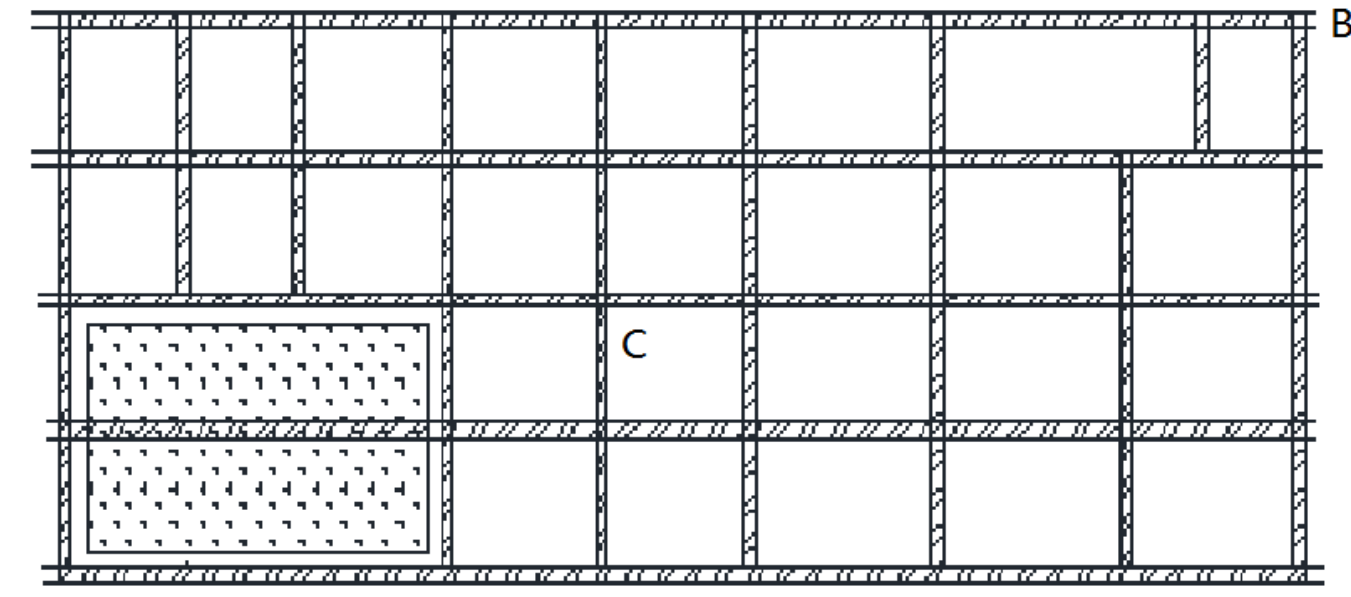

A

Figure3 Only open a horizontal road

Similarly, the number of optimal paths between A and $\mathrm{C}$ becomes 6 , and the number of optimal paths between A and B becomes 227 .

c. If the community is fully open. (Figure 4)

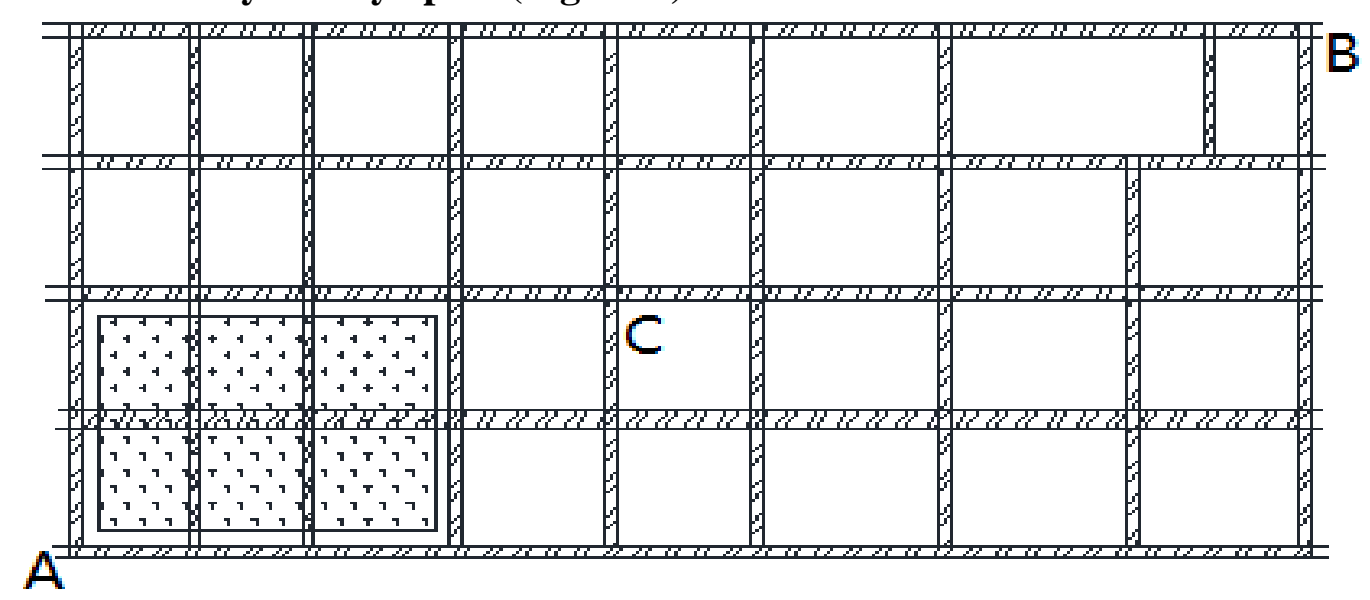

Figure 4 Community is fully open

After the community is fully open, the selectable path is obviously increased and the traffic efficiency is improved significantly. The number of optimal paths between $\mathrm{A}$ and $\mathrm{C}$ becomes 15 , and the number of optimal paths between A and B becomes 495 .

Using the road optimization formula, respectively, to calculate the different conditions of road optimization, the specific results in Table 1.

Table1 Summary of road optimization

\begin{tabular}{|c|c|c|c|c|}
\hline \multirow{2}{*}{$\begin{array}{c}\text { Degree of openness } \\
\text { Starting/end point }\end{array}$} & \multicolumn{2}{|c|}{ From A to C } & \multicolumn{2}{c|}{ From A to B } \\
\cline { 2 - 5 } & $\begin{array}{c}\text { The maximum } \\
\text { number of paths }\end{array}$ & $\begin{array}{c}\text { Optimization } \\
\text { degree }\end{array}$ & $\begin{array}{c}\text { The maximum } \\
\text { number of } \\
\text { paths }\end{array}$ & $\begin{array}{c}\text { Optimization } \\
\text { degree }\end{array}$ \\
\hline Closed & 4 & 0 & 171 & 0 \\
\hline $\begin{array}{c}\text { Only open a } \\
\text { horizontal road }\end{array}$ & 5 & 0.200 & 207 & 0.174 \\
\hline $\begin{array}{c}\text { Only open a vertical } \\
\text { road }\end{array}$ & 6 & 0.333 & 227 & 0.247 \\
\hline Fully open & 15 & 0.733 & 495 & 0.655 \\
\hline
\end{tabular}


From the analysis of Table 1 available, the degree of openness of the district is different, the degree of road optimization is also different. The greater the degree of openness, the greater the degree of road optimization. In addition, we can find that the degree of road optimization of A to C is greater than that of A to B. It also reflects the influence of community opening on the surrounding roads, that is, the closer to the open cell, the more big.

\section{Summary}

By using the road optimization degree to analyze the impact of community openness on road access, through the search and calculation of the optimal number of paths before and after the opening, we can see the degree of community openness to the road traffic, and then reflect the openness of the community to the surrounding roads influences.However, this calculation method is not combined with road conditions and actual capacity, and does not consider the complexity of the road network, only to a certain extent, reflect the surrounding road traffic situation. In general, community openness has a positive effect on road capacity, but does not rule out negative effects.

\section{Reference}

[1] Bing SU, Yin-feng XU. Effects of Residential Area and Residential Area on Traffic Accuracy of Grid Grid [J]. Systems Engineering, 2006, 24 (12): 33-39

[2] Peng Chen.Study on Road Network Planning in Small and Medium - sized Cities [D]. Huazhong University of Science and Technology, 2004.

[3] Gaqing Xiao.Study on the Impact of Community Opening on the Capacity of Roads [J]. Science and Technology Horizon, 2016 (26): 198-198. 